\title{
Simple dinitro substituted calix[4]arene forming a honeycomb-like architecture with hydrophobic channels $\uparrow$
}

\author{
Tobias Gruber, ${ }^{*}{ }^{a}$ Frank Eißmann, ${ }^{a}$ Margit Gruner, ${ }^{b}$ Luisa G. Heinz, ${ }^{a, t}$ Wilhelm \\ Seichter $^{a}$ and Edwin Weber* ${ }^{*}$ \\ ${ }^{a}$ TU Bergakademie Freiberg, Institut für Organische Chemie, Leipziger Str. 29, 09596 \\ Freiberg/Sachsen, Germany; \\ ${ }^{b}$ TU Dresden, Institut für Organische Chemie, Mommsenstr. 13, 01062 Dresden, Germany. \\ * To whom correspondence should be addressed. E-mail: tobias.gruber@ chemie-tu-freiberg.de; \\ edwin.weber@chemie.tu-freiberg.de. \\ * Present adress: Universität Basel, Institut für Anorganische Chemie, St. Johanns-Ring 19, 4056 \\ Basel, Switzerland. \\ $\dagger$ Electronic supplementary information (ESI) available: Representations of the acetone disorder \\ and packing structure of $\mathbf{1 a}$ (Fig. S1) as well as ${ }^{13} \mathrm{C}$ and ${ }^{1} \mathrm{H}$ NMR data of $\mathbf{1}$ in $\mathrm{CDCl}_{3}$ at $\mathrm{T}=295 \mathrm{~K}$ \\ (Tables S1 and S2). Crystallographic information files (CIF) have been deposited at the CCDC with \\ the reference numbers 787340, 787341 and 870204. For ESI see DOI: xxx xxx
}

A rather easy structured permethylated dinitro calix[4]arene was found to exhibit large, stable and rigid channels in the solid state. These were obtained as guest free as well as solvent filled species and proved to reversibly adsorb selected organic solvents. Combined use of QMB measurements and X-ray powder diffraction revealed the predominantly reversible interaction of dichloromethane vapour with the channel structure as well as the integrity of the nanopores during adsorption and desorption. Examination of the flexible host component by NMR spectroscopy revealed a mixture of interchanging conformational isomers which could explain the high sensitivity of the crystallization process from the employed solvents. 


\section{Introduction}

Microporous solids ${ }^{1}$ are still of an unbroken interest in supramolecular chemistry ${ }^{2}$ since they show outstanding properties, e.g. as catalysts or for the purpose of gas storage ${ }^{3}$ and nonlinear optics. ${ }^{4}$ Currently, the well-examined zeolites ${ }^{5}$ of purely inorganic nature go through an extension by the use of organic constituents, leading to the concept of metal-organic frameworks (MOFs) ${ }^{6}$ rapidly developing due to their promising applications. ${ }^{7}$ A third emerging class of porous materials is generated via self-assembling of purely organic compounds to yield the so-called 'organic zeolites ${ }^{8}{ }^{8}$ Hence, the creation of stable, non-penetrated or guest-independent non-collapsing porous materials is a highly topical challenge. In order to satisfy the requirements of such a porous material, the molecular components assembling the aggregate structure are expected to behave as rigid tectonic building units. ${ }^{9}$ In a few examples, derivatives of calixarenes that correspond to this concept have actually been described to yield a nanoporous supramolecular structure. ${ }^{10}$

Here, we report on a special case of a porous material featuring hydrophobic channels formed by a conformationally flexible, rather simple structured calix[4]arene (Scheme 1). Most remarkably, the channels can be obtained as guest free and solvent filled species or the channels are not formed at all dependent on the solvent of crystallization.

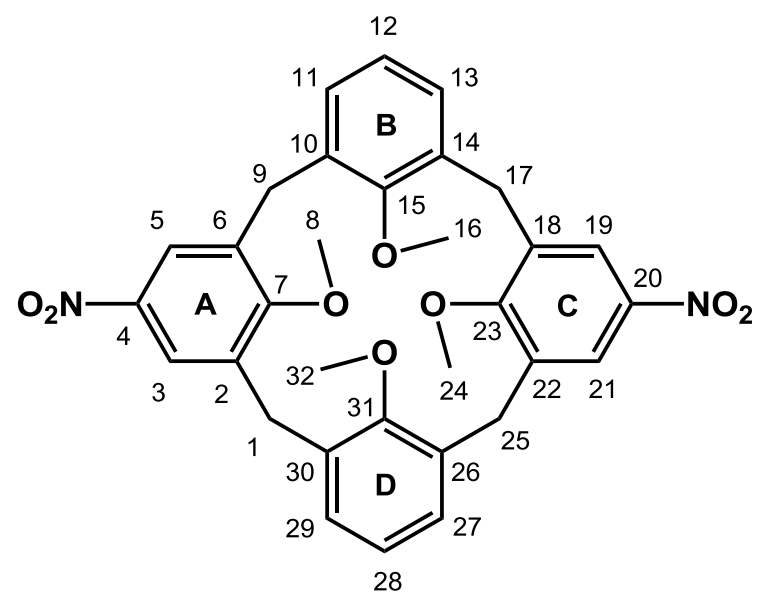

1

1a: $1 \cdot$ acetone $(3: 1)$

1b: $1 \cdot \mathrm{CHCl}_{3}(1: 1)$

Scheme 1. Compounds studied in this paper.

\section{Results and discussion}

The crystal structure of the solvent-free calixarene 1 and its inclusion compound with acetone (1a) have the rhombohedral space group $R-3$ with nearly identical cell parameters (Table 1). According to the three-fold crystal symmetry, the smallest supramolecular entities of the crystal structures are represented by cyclic hexamers of calixarene molecules (Fig. 1a) which are further arranged in a columnar fashion along the crystallographic $c$-axis thus creating channel-like voids with a diameter of approximately $6 \AA$. The total solvent accessible void volume per unit cell is 1675 
$\AA^{3}$ for $\mathbf{1}$ and $1612 \AA^{3}$ for $\mathbf{1 a}$ which corresponds to 12.0 and $11.6 \%$ of the respective cell volume. Due to the absence of strong hydrogen bond donors, each of the hexamers is stabilized by a close network of $\mathrm{C}-\mathrm{H} \cdots \mathrm{O}$ hydrogen bonds ${ }^{11}[d(\mathrm{H} \cdots \mathrm{O})=2.60-2.72 \AA]$ in which the nitro groups as well as methylene and arene hydrogens take part (Table 2).

Table 1. Crystal data and selected details of the data collection and refinement calculations of compounds $\mathbf{1}$, 1a and $\mathbf{1 b}$

\begin{tabular}{|c|c|c|c|}
\hline Compound & 1 & 1a & 1b \\
\hline empirical formula & $\mathrm{C}_{32} \mathrm{H}_{30} \mathrm{~N}_{2} \mathrm{O}_{8}$ & $\mathrm{C}_{32} \mathrm{H}_{30} \mathrm{~N}_{2} \mathrm{O}_{8} \cdot 0.33 \mathrm{C}_{3} \mathrm{H}_{6} \mathrm{O}$ & $\mathrm{C}_{32} \mathrm{H}_{30} \mathrm{~N}_{2} \mathrm{O}_{8} \cdot \mathrm{CHCl}_{3}$ \\
\hline formula weight & 570.58 & 589.94 & 689.95 \\
\hline crystal system & rhombohedral & rhombohedral & orthorhombic \\
\hline space group & $R-3$ & $R-3$ & $P b c a$ \\
\hline$a / \AA ̊$ & $39.4134(4)$ & $39.3244(3)$ & $16.1514(5)$ \\
\hline$b / \AA ̊$ & $39.4134(4)$ & $39.3244(3)$ & $16.4165(5)$ \\
\hline$c / \AA ̊$ & $10.4024(2)$ & $10.4186(2)$ & $24.4814(8)$ \\
\hline$\alpha /^{\circ}$ & 90.0 & 90.0 & 90.0 \\
\hline$\beta /{ }^{\circ}$ & 90.0 & 90.0 & 90.0 \\
\hline$y^{\circ}$ & 120.0 & 120.0 & 90.0 \\
\hline$V / \AA^{3}$ & 13994.3(3) & $13952.9(3)$ & $6491.2(4)$ \\
\hline$Z$ & 18 & 18 & 8 \\
\hline$F(000)$ & 5400 & 5592 & 2864 \\
\hline$D_{\mathrm{c}} / \mathrm{g} \mathrm{cm}^{-3}$ & 1.219 & 1.264 & 1.412 \\
\hline $\begin{array}{l}\left.\mu / \mathrm{mm}^{-1}\right) \\
\text { data collection: }\end{array}$ & 0.088 & 0.092 & 0.337 \\
\hline temperature/K & $93(2)$ & $103(2)$ & $100(2)$ \\
\hline no. of collected reflections & 114418 & 105784 & 45746 \\
\hline within the $\theta$-limit ${ }^{\circ}$ & $2.1-29.1$ & $2.1-28.6$ & $1.7-26.1$ \\
\hline index ranges $\pm h, \pm k, \pm l$ & $\begin{array}{l}-53 / 53,-53 / 52,- \\
14 / 11\end{array}$ & $-45 / 52,-51 / 52,-13 / 14$ & $\begin{array}{l}-19 / 19,-20 / 20,- \\
30 / 29\end{array}$ \\
\hline no. of unique reflections & 8290 & 7896 & 6445 \\
\hline $\begin{array}{l}R_{\text {int }} \\
\text { refinement calculations: } \\
\text { full-matrix least- squares } \\
\text { on all } F^{2} \text { values }\end{array}$ & 0.0477 & 0.0566 & 0.0369 \\
\hline weighting expression $w^{\mathrm{a}}$ & $\begin{array}{l}{\left[\sigma^{2}\left(F_{\mathrm{o}}^{2}\right)+(0.0877 P)^{2}\right.} \\
+17.1128 P]^{-1}\end{array}$ & $\begin{array}{l}{\left[\sigma^{2}\left(F_{\mathrm{o}}^{2}\right)+(0.0600 P)^{2}\right.} \\
+22.8232 P]^{-1}\end{array}$ & $\begin{array}{l}{\left[\sigma^{2}\left(F_{\mathrm{o}}^{2}\right)+(0.0957 P)^{2}\right.} \\
+9.2233 P]^{-1}\end{array}$ \\
\hline no. of refined parameters & 383 & 399 & 444 \\
\hline $\begin{array}{l}\text { no. of } \mathrm{F} \text { values used }[I>2 \sigma(I)] \\
\text { final } R \text {-Indices }\end{array}$ & 6448 & 5211 & 5278 \\
\hline$R\left(=\Sigma|\Delta F| / \Sigma\left|F_{\mathrm{O}}\right|\right)$ & 0.0496 & 0.0531 & 0.0678 \\
\hline$w R$ on $F^{2}$ & 0.1494 & 0.1462 & 0.2150 \\
\hline$S$ (=Goodness of fit on $F^{2}$ ) & 0.995 & 1.041 & 1.284 \\
\hline final $\Delta \rho_{\max } / \Delta \rho_{\min } / \mathrm{e} \AA^{-3}$ & $0.55 /-0.36$ & $0.44 /-0.29$ & $0.88 /-0.53$ \\
\hline
\end{tabular}

${ }^{\mathrm{a}} P=\left(F_{\mathrm{o}}^{2}+2 F_{\mathrm{c}}^{2}\right) / 3$. 
Table 2. Distances $(\AA)$ and angles $\left(^{\circ}\right)$ of hydrogen bonds of $\mathbf{1}$ and its inclusion compounds with acetone (1a) and chloroform (1b)

\begin{tabular}{|c|c|c|c|c|}
\hline \multirow{2}{*}{ Atoms } & \multirow{2}{*}{ Symmetry } & \multicolumn{2}{|c|}{ Distances $(\AA)$} & \multirow{2}{*}{$\begin{array}{c}\text { Angles }\left({ }^{\circ}\right) \\
\text { D-H } \cdots \text { A }\end{array}$} \\
\hline & & $\mathrm{D} \cdots \mathrm{A}$ & $\mathrm{H} \cdots \mathrm{A}$ & \\
\hline \multicolumn{5}{|l|}{1} \\
\hline $\mathrm{C}(9)-\mathrm{H}(9 \mathrm{~A}) \ldots \mathrm{O}(2)$ & $0.33+y, 0.66-x+y, 0.66-z$ & $3.451(2)$ & 2.63 & 140 \\
\hline $\mathrm{C}(1)-\mathrm{H}(1 \mathrm{~B}) \ldots \mathrm{O}(3)$ & $0.33+x-y,-0.33+x, 0.66-z$ & $3.439(2)$ & 2.63 & 139 \\
\hline $\mathrm{C}(29)-\mathrm{H}(29) \ldots \mathrm{O}(5)$ & $0.33+x-y,-0.33+x, 0.66-z$ & $3.282(2)$ & 2.61 & 128 \\
\hline $\mathrm{C}(11)-\mathrm{H}(11) \ldots \mathrm{O}(6)$ & $0.33+y, 0.33-x+y, 0.66-z$ & $3.349(2)$ & 2.70 & 127 \\
\hline \multicolumn{5}{|l|}{ 1a } \\
\hline $\mathrm{C}(9)-\mathrm{H}(9 \mathrm{~A}) \ldots \mathrm{O}(1)$ & $1+x, 1-x+y, 2-z$ & $3.416(3)$ & 2.61 & 138 \\
\hline $\mathrm{C}(1)-\mathrm{H}(1 \mathrm{~B}) \ldots \mathrm{O}(2)$ & $x-y,-1+x, 2-z$ & $3.428(3)$ & 2.62 & 139 \\
\hline $\mathrm{C}(29)-\mathrm{H}(29) \ldots \mathrm{O}(5)$ & $x-y,-1+x, 2-z$ & $3.343(3)$ & 2.70 & 126 \\
\hline $\mathrm{C}(11)-\mathrm{H}(11) \ldots \mathrm{O}(6)$ & $1+x, 1-x+y, 2-z$ & $3.264(3)$ & 2.60 & 127 \\
\hline \multicolumn{5}{|l|}{$1 \mathrm{~b}$} \\
\hline $\mathrm{C}(17)-\mathrm{H}(17 \mathrm{~A}) \ldots \mathrm{O}(5)$ & $0.5+x, y, 0.5-z$ & $3.414(4)$ & 2.49 & 156 \\
\hline $\mathrm{C}(1 \mathrm{G})-\mathrm{H}(1 \mathrm{G}) \ldots \mathrm{O}(5)$ & $-0.5+x, y, 0.5-z$ & $3.106(5)$ & 2.44 & 123 \\
\hline $\mathrm{C}(1 \mathrm{H})-(\mathrm{H} 1 \mathrm{H}) \ldots \mathrm{O}(5)$ & $-0.5+x, y, 0.5-z$ & $3.361(4)$ & 2.56 & 137 \\
\hline $\mathrm{C}(25)-\mathrm{H}(25 \mathrm{~B}) \ldots \mathrm{O}(6)$ & $2-x,-0.5+y, 0.5-z$ & $3.263(5)$ & 2.51 & 133 \\
\hline $\mathrm{C}(11)-(\mathrm{H} 11) \ldots \mathrm{O}(8)$ & $2-x, 0.5+y, 0.5-z$ & $3.378(5)$ & 2.64 & 135 \\
\hline $\mathrm{C}(1 \mathrm{G})-(\mathrm{H} 1 \mathrm{G}) \ldots \mathrm{O}(8)$ & $-0.5+x, y, 0.5-z$ & $3.332(5)$ & 2.61 & 130 \\
\hline $\mathrm{C}(1 \mathrm{H})-\mathrm{C}(1 \mathrm{H}) \ldots \mathrm{O}(8)$ & $-0.5+x, y, 0.5-z$ & $3.420(5)$ & 2.64 & 135 \\
\hline $\mathrm{C}(27)-\mathrm{H}(27) \ldots \mathrm{Cl}(2 \mathrm{H})$ & $1.5-x,-0.5+y, 1-z$ & $2.686(5)$ & 1.84 & 147 \\
\hline $\mathrm{C}(1 \mathrm{H})-\mathrm{Cl}(3 \mathrm{H}) \ldots \mathrm{Cl}(3 \mathrm{H})$ & $1-x, y, 1-z$ & $4.387(5)$ & $2.902(5)$ & $141.7(1)$ \\
\hline
\end{tabular}

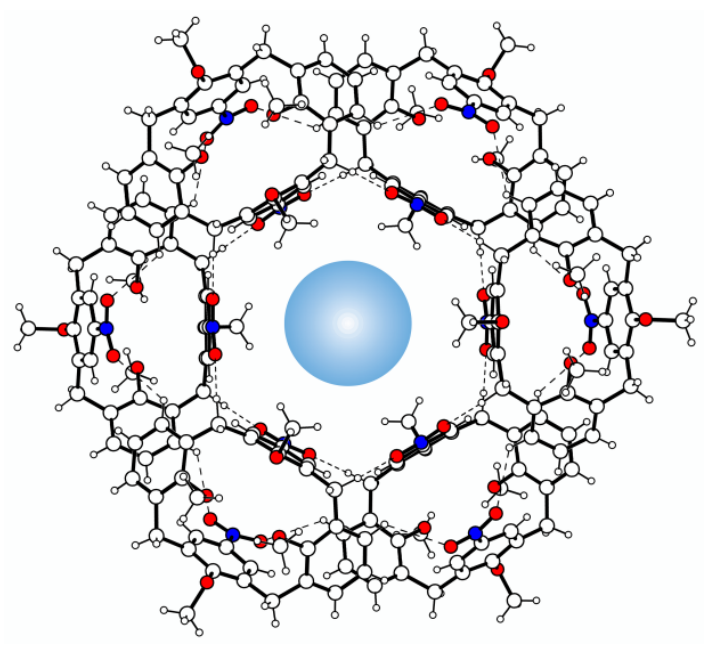

(a)

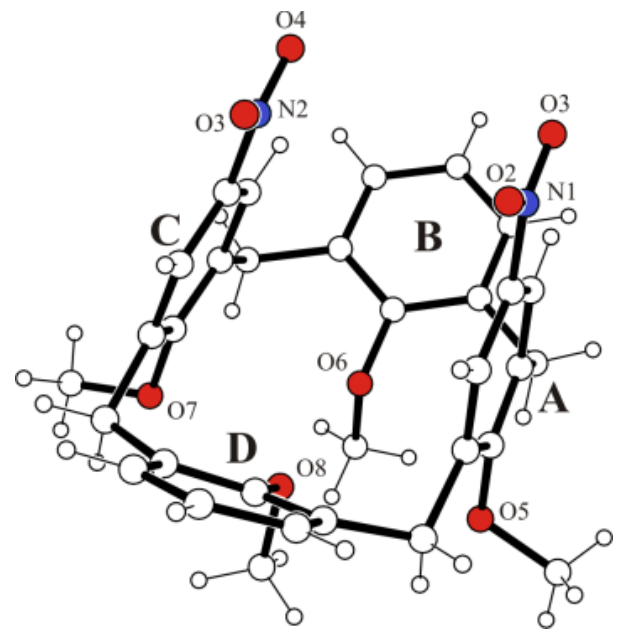

(b)

Fig. 1. a) Structure of the hexameric calixarene unit of 1a viewed down the crystallographic $c$-axis. Broken lines represent hydrogen bonds. Because of the high grade of disorder, the acetone molecule in the channel have been omitted for clarity and is marked by a light blue circle. A detailed representation of the acetone disorder is shown in Fig. S1. b) Molecular structure of $\mathbf{1 .}$ 
When a chloroform/toluene mixture was used for crystallization, the crystal structure turned out to be the guest-free species, viz. the cavity spanned by six calixarene molecules is empty. On the other hand, crystallization from acetone/toluene yielded an isostructural 3:1 exo-complex with acetone (1a), showing the acetone molecule disordered around a three-fold rotational inversion axis within this very cavity (Fig. S1, ESI $\dagger$ ). The partially solvated structure can be explained by an incomplete evaporation of the acetone during or after formation of the crystals and is probably associated with its perfect match and slightly better host-guest van der Waals interactions in comparison to chloroform or toluene.

On closer examination, one can find that in both structures of $\mathbf{1}$, the calixarenes are deviating significantly from the characteristic cup-shapes and adopt extremely pinched cone conformations $\left(\mathrm{C}_{2 \mathrm{v}}\right.$ symmetry, Fig. 1b). In general, the adoption of a cone conformation of the flexible tetramethoxy calix[4]arenes in the solid state is, with exception of the respective sodium complex ${ }^{12}$, a rather atypical behaviour as previously shown by our and other groups. ${ }^{13}$ However so far, only phenyl substituted and some laterally derivatized tetramethoxy calixarenes were found to be in the cone conformation in the crystal. ${ }^{14}$ Furthermore, in the present structures of title compound $\mathbf{1}$, the cone conformation is rather impaired and could probably be best described as inverted: the arene units $\mathrm{A}$ and $\mathrm{C}$ are almost coplanar (interplanary angles $16.7^{\circ}$ and $16.0^{\circ}$, resp.) with the nitro groups pointing at each other, forcing the aromatic rings B and D to open widely (apex angles $115.1^{\circ}$ and $114.7^{\circ}$, resp.) (Table 3 ). This striking arrangement of the aromatic building units is accompanied by a narrowing of the intramolecular cavity, preventing cavitate formation with the respective solvent molecules and can be explained on the one hand by the absence of coordinating substituents at the lower rim and on the other hand by strong sterical demands of the crystal packing.

Table 3. Selected conformational parameters of the compounds studied in this paper

\begin{tabular}{|c|c|c|c|}
\hline compound & 1 & $1 \mathbf{a}$ & $1 \mathbf{b}$ \\
\hline \multicolumn{4}{|c|}{ interplanar angles $\left({ }^{\circ}\right)^{\mathrm{a}}$} \\
\hline $\mathrm{A} / \mathrm{C}$ & $16.7(1)$ & $16.0(1)$ & $24.9(1)$ \\
\hline $\mathrm{B} / \mathrm{D}$ & $64.9(1)$ & $65.3(1)$ & $70.6(1)$ \\
\hline $\mathrm{mpla} / \mathrm{A}$ & $84.7(1)$ & $85.2(1)$ & $78.0(1)$ \\
\hline mpla/B & $30.4(1)$ & $34.6(1)$ & $24.6(1)$ \\
\hline $\mathrm{mpla} / \mathrm{C}$ & $78.6(1)$ & $78.9(1)$ & $77.1(1)$ \\
\hline $\mathrm{mpla} / \mathrm{D}$ & $34.5(1)$ & $30.7(1)$ & $85.0(1)$ \\
\hline ring $\mathrm{A} / \mathrm{NO}_{2}$ group & $3.5(2)$ & $2.8(1)$ & $22.1(1)$ \\
\hline ring $\mathrm{C} / \mathrm{NO}_{2}$ group & $6.4(2)$ & $6.6(2)$ & $13.4(1)$ \\
\hline \multicolumn{4}{|c|}{$\begin{array}{l}\text { aromatic rings: ring } A: C(2) \ldots C(7) \text {; ring } B: C(10) \ldots C(15) \text {; } \\
\text { ring } C: C(18) \ldots C(23) \text {; ring } D: C(26) \ldots C(31) .{ }^{b} \text { Best plane } \\
\text { through atoms } C(1), C(9), C(17) \text { and } C(25) .\end{array}$} \\
\hline
\end{tabular}


As depicted in Fig. 2, the overall packing structure is characterized by a columnar arrangement of calixarene hexamers which extends along the crystallographic $c$-axis. Because of the relatively low polar nature of the hexamers, the crystal structure is predominantly stabilized by van der Waals type forces and weak intermolecular packing interactions. The surface of the hexameric unit as well as the interior of its cavity is formed by the methoxy groups, creating a more or less hydrophobic environment.

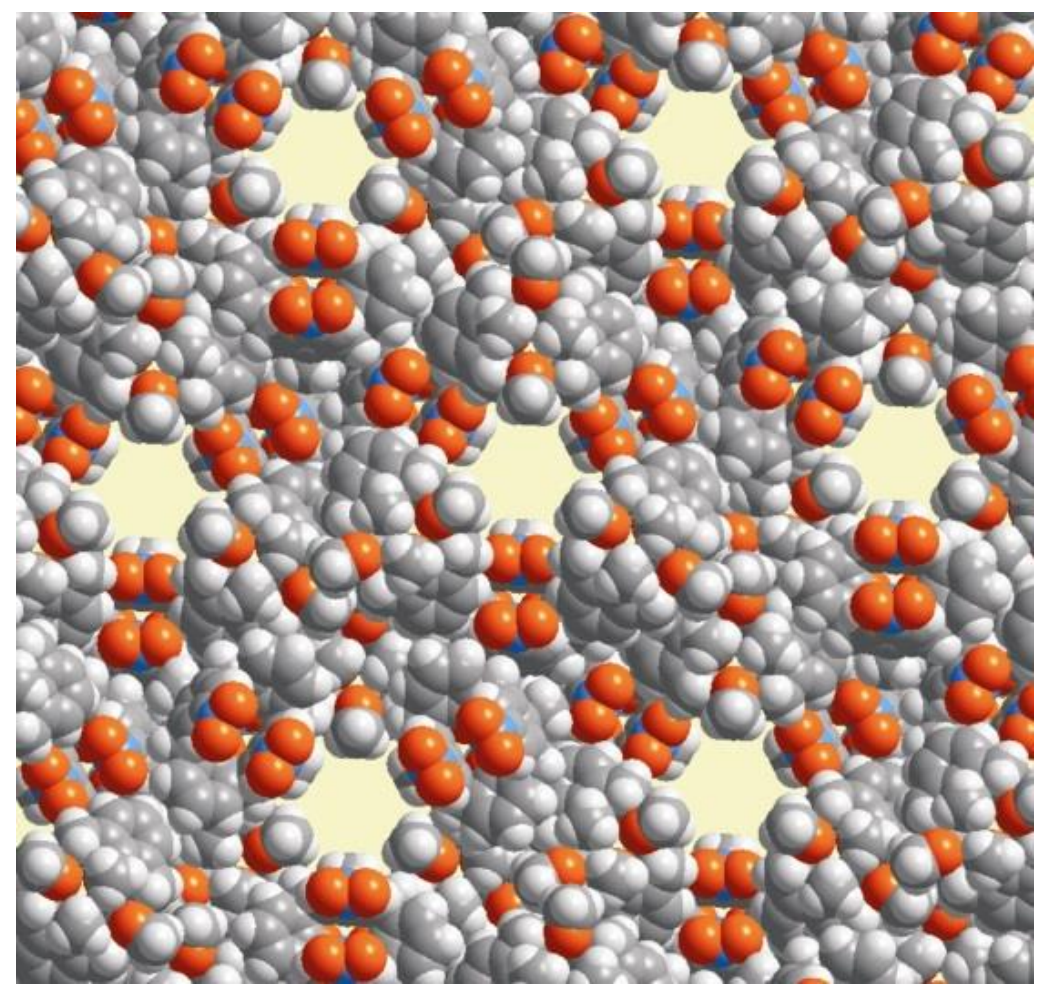

Fig. 2. Structure of the crystal lattice of $\mathbf{1}$ viewed down the crystallographic $c$-axis. Corbon atoms are displayed as grey, oxygens as red spheres.

Surprinsingly, only slight changes of the solvent system used for crystallization of the title compound, result in a completely different crystal structure. When we used chloroform $/ n$-hexane instead of chloroform/toluene, a 1:1 inclusion compound of 1 with $\mathrm{CHCl}_{3}$ (1) $)$ in the orthorhombic space group $\mathrm{Pbca}$ was recovered. Remarkably, the calixarene adopts in this case the partial cone conformation (Fig. 3) with interplanary angles of 70.6(1) for rings B/D and 24.9(1) ${ }^{\circ}$ for rings $\mathrm{A} / \mathrm{C}$, respectively. Like in the above cone form, the very narrow cavity prohibits the formation of an endo complex with solvent molecules. And yet, in the present case, chloroform is clathrat-like accommodated in the lattice voids. The guest molecule shows a twofold disorder with SOF's of 0.858 (C1G, Cl1G, Cl2G, Cl3G, H1G) and $0.142(\mathrm{C} 1 \mathrm{H}, \mathrm{Cl1H}, \mathrm{Cl} 2 \mathrm{~S}, \mathrm{Cl} 3 \mathrm{H}, \mathrm{H} 1 \mathrm{H})$, respectively. Interestingly, within the packing of the sheet-like arranged calixarene molecules the two differently occupied positions of the chloroform display distinct intermolecular interactions. For disorder position 1 (Fig. 4a), the $\mathrm{CHCl}_{3}$ guest is only engaged into one bifurcated $\mathrm{C}-\mathrm{H} \cdots \mathrm{O}$ hydrogen bond, ${ }^{16}$ though in the minor occupied chloroform position 2, additional strong $\mathrm{C}-\mathrm{H} \cdots \mathrm{Cl}$ hydrogen bonds ${ }^{15}$ $[d(\mathrm{H} \cdots \mathrm{Cl}) 1.84 \AA]$ and weak head-on $\mathrm{Cl} \cdots \mathrm{Cl}$ contacts $^{16}[d(\mathrm{Cl} \cdots \mathrm{Cl}) 2.902(5) \AA]$ can be observed (Fig. 4b). The interconnection of the calixarene molecules among themselves is restricted to two 
weak C-H...O-contacts involving two of the methylene bridges and two oxygen atoms of the nitro groups.

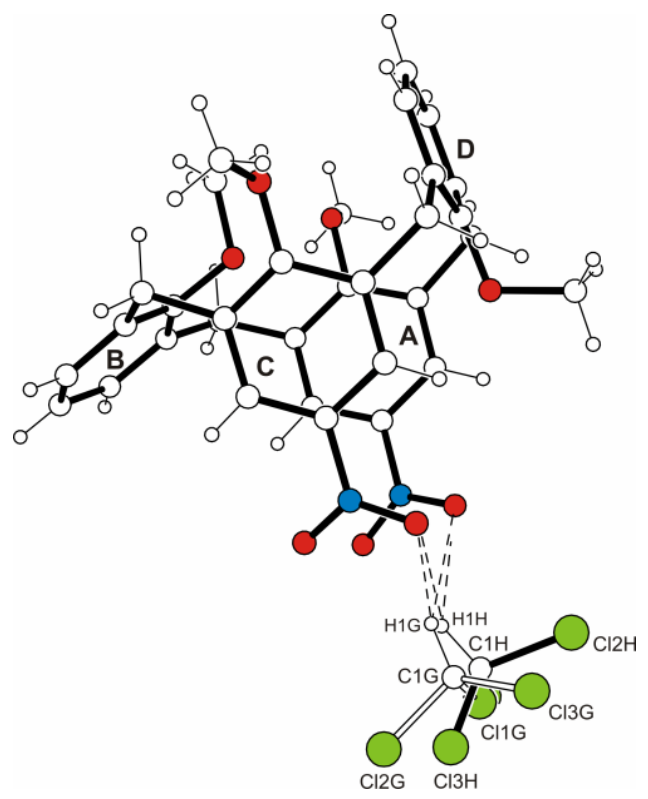

Figure 3

Fig. 3. Molecular structure of the 1:1 complex of $\mathbf{1}$ with $\mathrm{CHCl}_{3}$ (1b). Broken lines represent hydrogen bonds. The two disorder sites of the guest molecule are marked by different styles of bonds. 


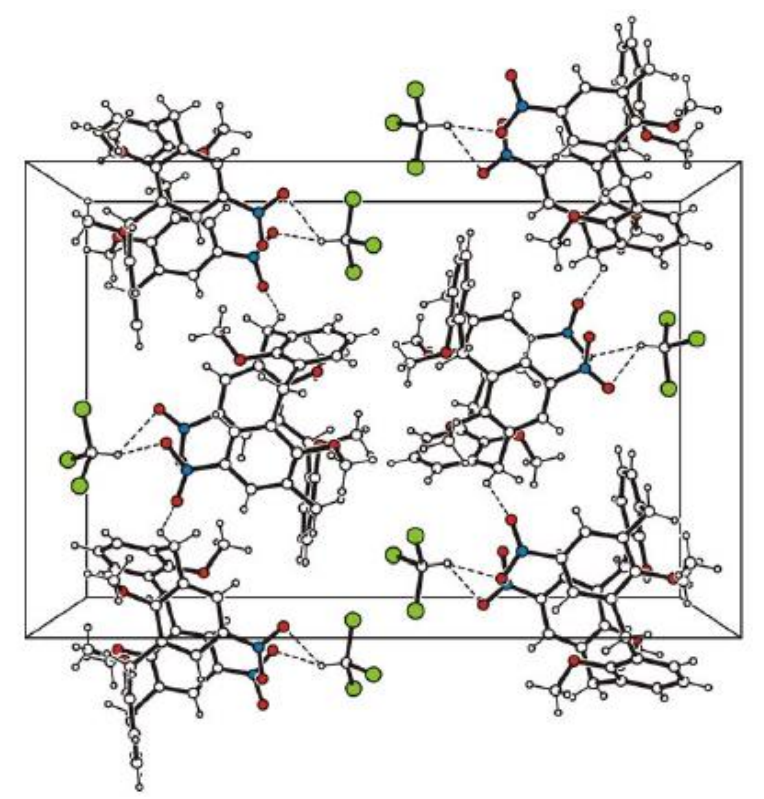

a)

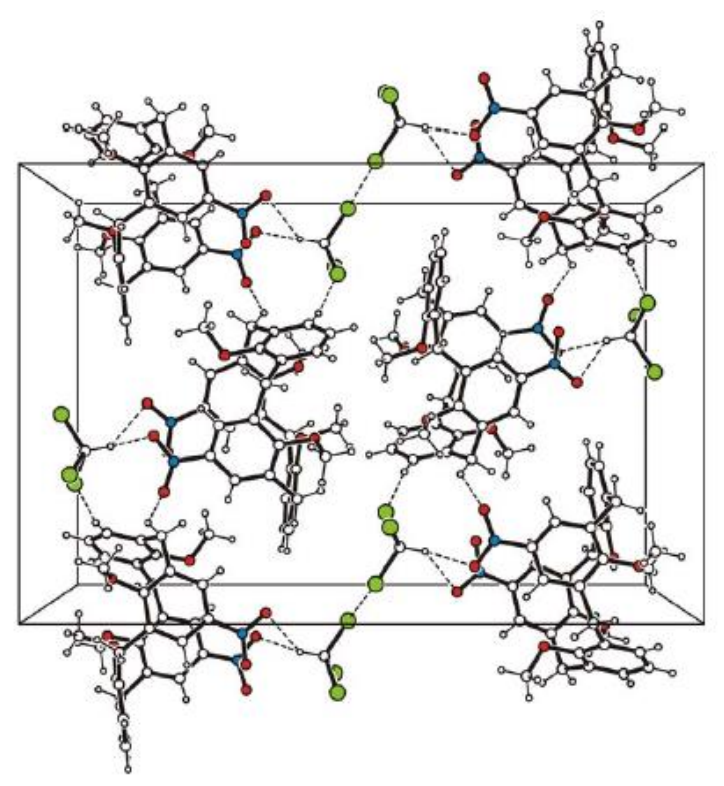

b)

Fig. 4. Packing structure of the 1:1 complex of 1 with $\mathrm{CHCl}_{3}(\mathbf{1 b})$ viewed down the crystallographic $a$-axis with the respective major-occupancy component (a) and minor-occupancy-component of the solvent molecule (b). Broken lines indicate intermolecular interactions.

Above findings stimulated a thorough conformational analysis of the title molecule in solution. A complex pattern of signals in the $\mathrm{NMR}$ spectra in $\mathrm{CDCl}_{3}$ and $\mathrm{CDCl}_{3}$ /toluene- $\mathrm{d}_{8}$ indicates the existence of different conformers. Detailed 2D NMR study using COSY, ${ }^{1} \mathrm{H} /{ }^{13} \mathrm{C}$-correlated HSQC and HMBC as well as subsequently applied NOESY and ROESY methods leads to a full assignment of the conformative structures (Tables S1 and S2, ESI $\dagger$ ) and their distribution in 
solution, summarized in Fig. 5 and Table 4. In general, only cone and two partial cone conformations are observed in this system, though potential alternate conformations are not detected in any case. For $\mathbf{1}$ in chloroform/toluene (from which the respective guest free channel structure was obtained) all three forms occur in a 1:2:2 ratio at room temperature with $21 \%$ cone, $39 \%$ partial cone 1 and $40 \%$ partial cone 2 . By using $\mathrm{CDCl}_{3} / n$-hexane- $\mathrm{d}_{14}$ or pure chloroform, the ratios of the different conformers not change significantly. In all cases, the somewhat non-polar partial cone species are favoured, which leads also to the manifestation of one of these conformations in the solid state in the case of crystallization from chloroform $/ n$-hexane. However, crystal formation of $\mathbf{1}$ in chloroform/toluene prefers the cone form of the title molecule. It seems feasible that the chloroform evaporates more easily, leaving behind a solution of $\mathbf{1}$ rich in toluene. In that, the formation of 1:1 inclusion complexes of the title compound with toluene can be discussed, accompanied by a conformational swing towards the cone form, which is also present in the inclusion compounds $\mathbf{1 a}$ and $\mathbf{1 b}$. The subtle influence of solvents and respective mixtures on the solid state behaviour of a calixarene was only recently discussed in the literature. ${ }^{17}$

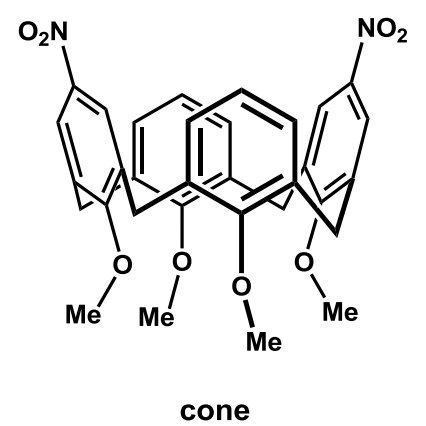

conformation in X-ray structures of $\mathbf{1}$ and $\mathbf{1 a}$
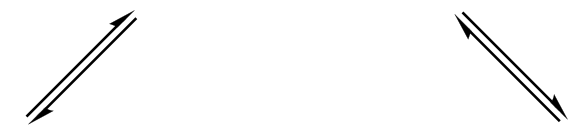

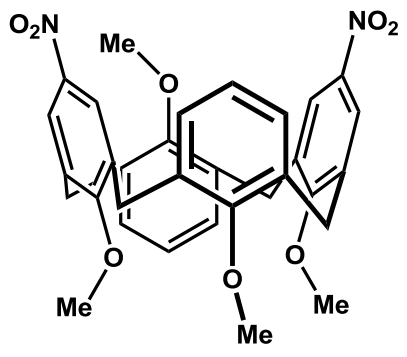

paco1

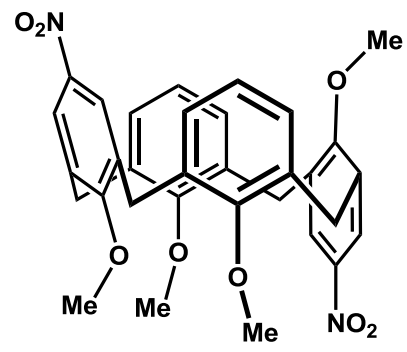

paco2

conformation in

X-ray structure of $\mathbf{1 b}$

Fig. 5. Conformational transformations of $\mathbf{1}$ in solution. 
Table 4. Distribution of the conformers of 1 in solutions of $\mathrm{CDCl}_{3}, \mathrm{CDCl}_{3} /$ toluene- $\mathrm{d}_{8}$ or $\mathrm{CDCl}_{3} / n$ hexane- $\mathrm{d}_{14}$ at different temperature $(\mathrm{mol} \%)$. Alternate conformations were not observed. Please note, that it was not possible to determine the conformational distribution of $\mathbf{1}$ in pure toluene- $\mathrm{d}_{8}$ as the compound is only sparingly soluble in this solvent

\begin{tabular}{|c|c|c|c|}
\hline conformer & cone & $\begin{array}{l}\text { partial } \\
\text { cone } 1\end{array}$ & $\begin{array}{l}\text { partial } \\
\text { cone } 2\end{array}$ \\
\hline $\begin{array}{l}\mathrm{CDCl}_{3} / \text { toluene- } \mathrm{d}_{8}, \\
\mathrm{~T}=295 \mathrm{~K}\end{array}$ & 21 & 39 & 40 \\
\hline $\begin{array}{l}\mathrm{CDCl}_{3} / \text { toluene- }_{8}, \\
\mathrm{~T}=262 \mathrm{~K}\end{array}$ & 20 & 48 & 32 \\
\hline $\begin{array}{l}\mathrm{CDCl}_{3} \\
\mathrm{~T}=295 \mathrm{~K}\end{array}$ & 20 & 43 & 37 \\
\hline $\begin{array}{l}\mathrm{CDCl}_{3}, \\
\mathrm{~T}=262 \mathrm{~K}\end{array}$ & 19 & 48 & 33 \\
\hline $\begin{array}{l}\mathrm{CDCl}_{3} / n \text {-hexane- } \mathrm{d}_{14} \\
\mathrm{~T}=295 \mathrm{~K}\end{array}$ & 23 & 43 & 34 \\
\hline $\begin{array}{l}\mathrm{CDCl}_{3} / n \text {-hexane- } \mathrm{d}_{14} \\
\mathrm{~T}=262 \mathrm{~K}\end{array}$ & 21 & 43 & 36 \\
\hline
\end{tabular}

For a general estimation of the conformational changes caused by the nitration of the parent tetramethoxy calix[4]arene, it seemed reasonable to include the conformer distribution of the respective unsubstituted ${ }^{18}$ and tetranitro ${ }^{19}$ calix[4]arenes (22\% cone, $78 \%$ partial cone and $7 \%$ cone, $93 \%$ partial cone, respectively, vs. $79 \%$ partial cone and $21 \%$ cone for $\mathbf{1}$ ). Hence, the conformational behaviour of the tetramethoxycalix[4]arene in $\mathrm{CDCl}_{3}$ varies only little by introduction of two nitro groups at the upper rim. However, exhaustive nitration of the upper rim increases the rate of partial cone conformation up to $93 \%$.

In a next step, a quartz micro balance device ${ }^{20}$ was used to determine the sorptive property of apo-host 1 towards varying solvent vapours being exemplary of high and low polarity as well as of a protic and aprotic nature ( $n$-hexane, dichloromethane, tetrahydrofuran, acetone, ethanol, toluene, cyclohexene and cyclohexane). The results obtained are as follows (Fig. 6): the vapours of the more or less polar aprotic solvents dichloromethane, acetone and tetrahydrofuran are adsorbed rather intensively, while the adsorption of the polar protic (ethanol) and non-polar solvents ( $n$-hexane, cyclohexene, cyclohexane, toluene) is not significant. All this behaviour is likely to be connected with the polarity interrelation between the adsorbed compound and solid adsorbent. 


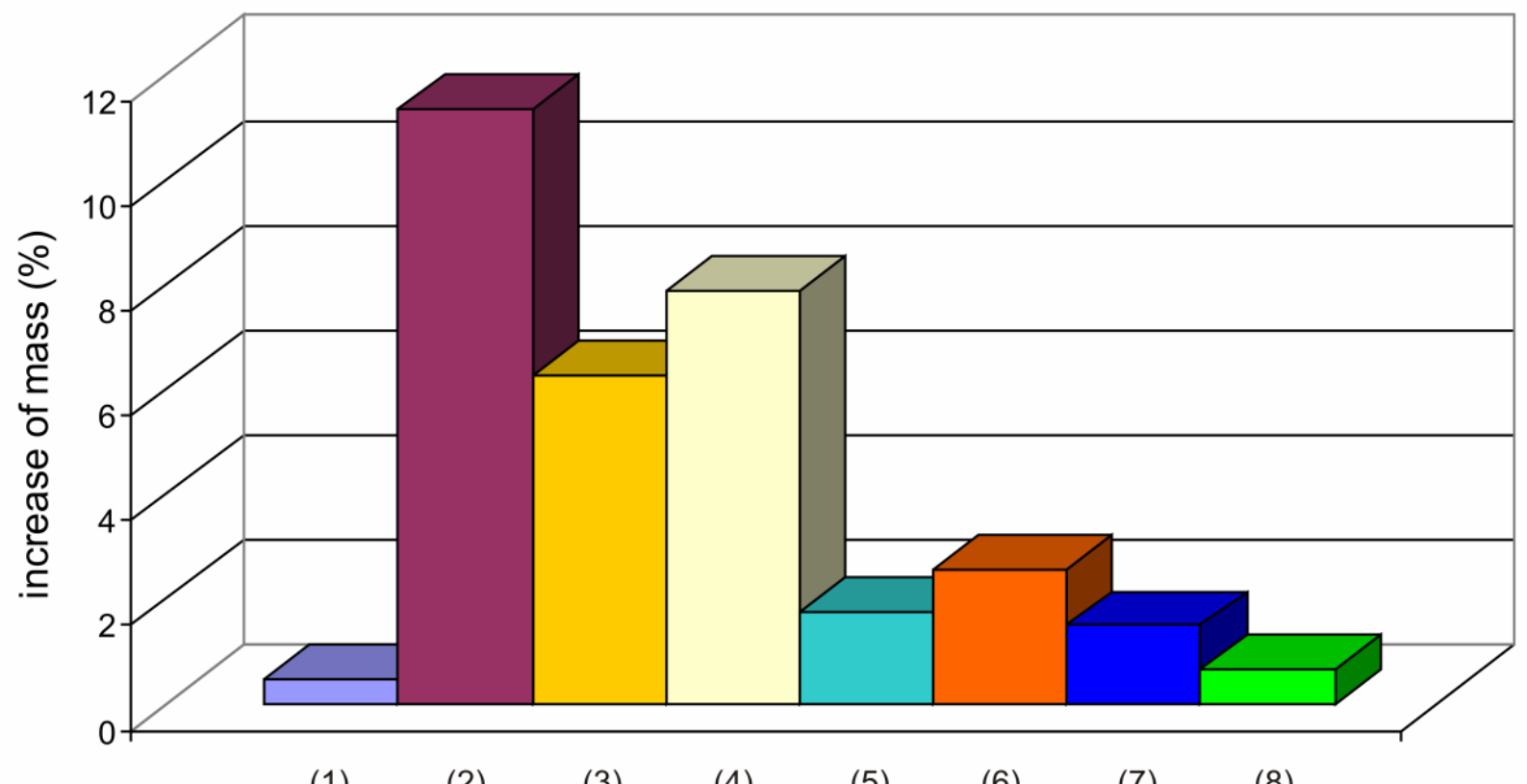

(1)

(2)

(3)

(4)

(5)

(6)

(7)

(8)

Fig. 6. Responses of a QMB device coated with 1 for vapours of various solvents: (1) $n$-hexane, (2) dichloromethane, (3) tetrahydrofuran, (4) acetone, (5) ethanol, (6) toluene, (7) cyclohexene, (8) cyclohexane.

As demonstrated by previous studies, ${ }^{21}$ depending on size and interaction of the analyte molecules, the regeneration step of a quartz mirco balance does not always return the sensor frequency to the starting value, which is undoubtedly necessary for a possible application of this nanoporous material for the sensing or storage of organic vapours. As shown in Fig. 7 for dichloromethane as an example, the rate of regeneration, viz. the return of the frequency of the oscillating quartz to the original level, for this special case is larger than $99.99 \%$. Hence, the pores display a rather low host affinity, which is a consequence of missing interaction between host and guest, but nevertheless, enable fast and reversible guest diffusion. 


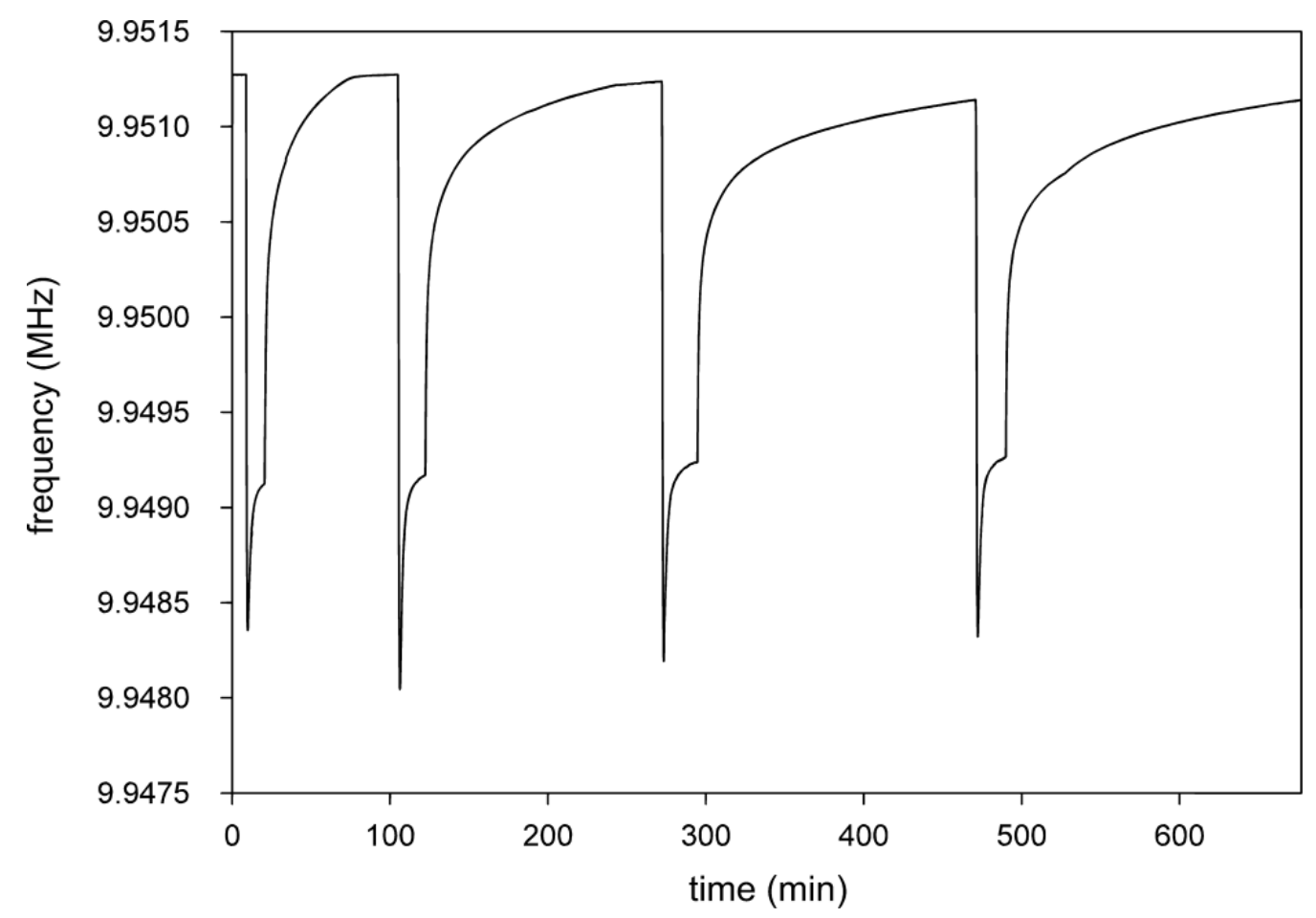

Fig. 7. QMB dichloromethane vapour sorption measurements of a coating of 1 showing four adsorption/desorption cycles. Solvent adsorption leads to a spontaneous decrease in frequency and finally a frequency equilibration. Desorption and the related approach to equilibrium frequency occur more slowly.

Despite the weak intermolecular interactions within the solid, the macroscopic crystals of guestfree 1 turned out to be perfectly air-stable. To demonstrate the preservation of the nanopores even after adsorption and desorption of organic guests, powder diffraction was used, whose results are displayed in Fig. 8. Comparison of X-ray powder diffraction patterns of $\mathbf{1}$ before adsorption and after desorption of dichloromethane reveals no significant differences and suggests the integrity of the nanopores even in the presence of solvent vapour. 


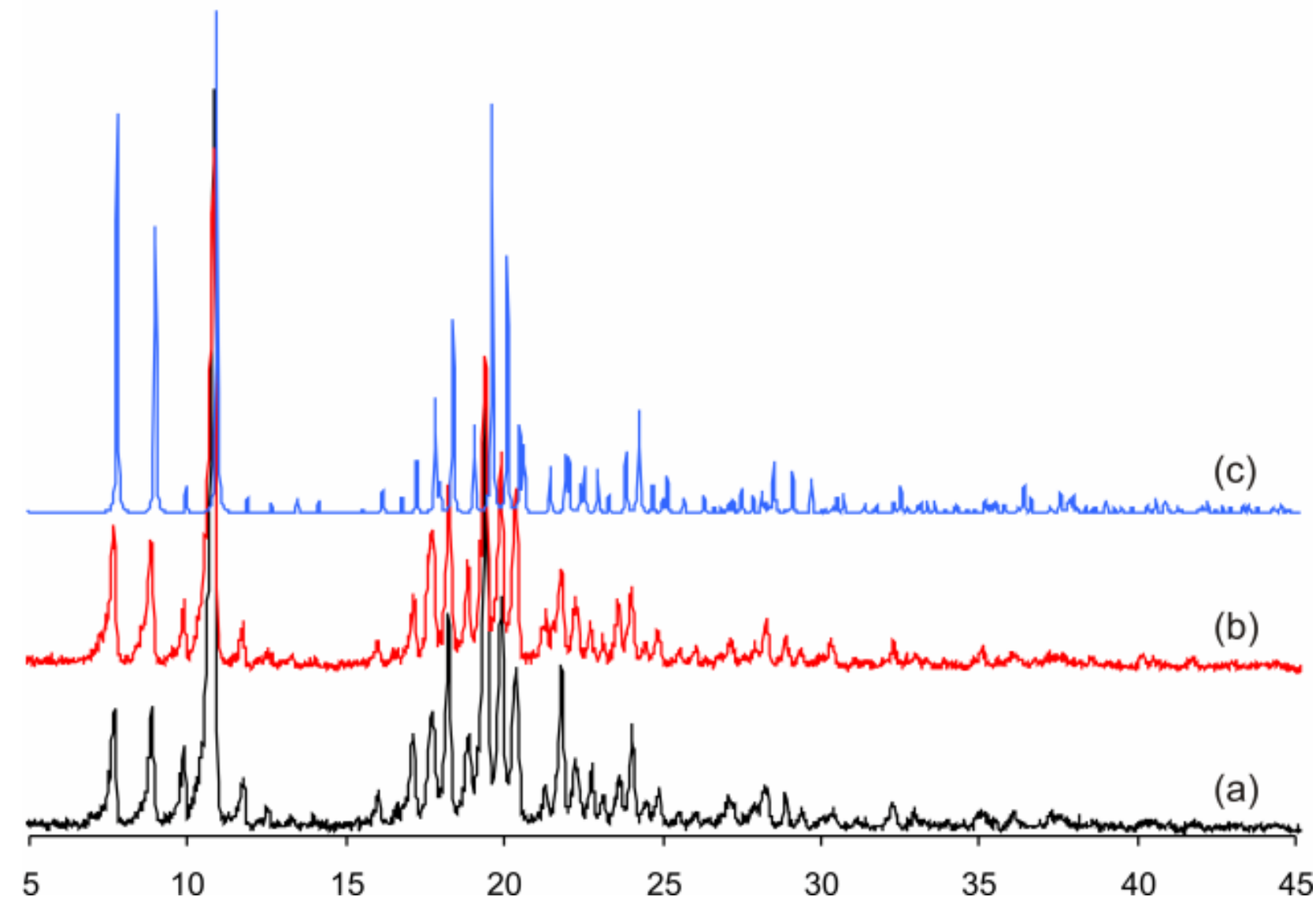

Fig. 8. X-ray powder pattern of $\mathbf{1}$ before adsorption (a) and after desorption (b) of dichloromethane. For comparison, (c) shows the pattern calculated from the single crystal analysis of the guest-free structure of the title compound.

\section{Conclusion}

In summary, we have identified a total organic framework featuring large, stable and rigid channels, being composed of hexameric units of a dinitro tetramethoxy calixarene, which was also examined by NMR spectroscopy revealing a high sensitivity of the crystallization process from the employed solvents. In order to elucidate the adsorption properties of the nanoporous material in hands, we combined the use of QMB measurements and X-ray powder diffraction. By examining selected organic solvent vapours, dichloromethane turned out to be the most promising candidate for further inclusion experiments, which revealed the predominantly reversible interaction of the dichloromethane vapour with the channel structure as well as the integrity of the nanopores during adsorption and desorption. In subsequent studies, we will elucidate to which extent the title calixarene can be derivatised without loosing the ability to form a nanoporous material in the solid state. 


\section{Experimental section}

\section{Materials}

The title calixarene 1, possessing only two distal nitro groups attached to the upper rim site and four methoxy groups in lower rim position, was obtained straightforward by nitration of the corresponding dimethoxy calix[4]arene ${ }^{22}$ followed by exhaustive methylation using methyl iodide and potassium carbonate. ${ }^{23}$ Thereupon, compound $\mathbf{1}$ was dissolved in mixtures of chloroform/toluene (1:1) or acetone/toluene (1:1), respectively, and the solvents were allowed to evaporate completely, which afforded diffraction quality single crystals of $\mathbf{1}$ and $\mathbf{1 a}$ in both cases. When we used chloroform/n-hexane instead chloroform/toluene, a 1:1 inclusion compound of 1 with $\mathrm{CHCl}_{3}(\mathbf{1 b})$ was recovered.

\section{$\mathrm{X}$-ray crystal structure analysis}

Diffraction data were collected on a Bruker Kappa APEX II CCD diffractometer with $\mathrm{MoK}_{\alpha}$ radiation $(\lambda=0.71073 \AA)$. Intensities were corrected for absorption using the multi-scan technique SADABS ${ }^{24}$ Structure solution and refinement were carried out using SHELXS-97 and SHELXL-97. ${ }^{25}$ All non-hydrogen atoms were refined anisotropically (except for the case of the disordered acetone in 1a); $\mathrm{H}$ atoms were fixed in calculated positions; the $\mathrm{H}$ atoms of the acetone molecule in 1a were not included in the refinement.

\section{QMB vapour sorption measurments}

The experimental setup of the quartz crystal microbalance consists of two $10 \mathrm{MHz}$ standard electronic quartzes with gold electrodes (FOQ Piezo Technik, Germany). One of them is uncoated and used as reference; the other one is coated with the receptor. Both quartzes are located in a thermostated metal block (controlled to $25^{\circ} \mathrm{C}$ by a water thermostat). The measurements are carried out with a constant flow of synthetic air. The resonance frequencies of the quartzes are measured by a multi-channel frequency counter (HKR sensor systems Munich, Germany) with a resolution of 1 $\mathrm{Hz}$. The frequency data can be read by the computer via a serial interface and the coating of the quartzes was performed by dipping the quartz into $10 \mathrm{mM}$ solution of compound $\mathbf{1}$ in chloroform/toluene (1:1). According to the Sauerbrey equation, ${ }^{26}$ the measured frequency change is proportional to the increase of mass caused by the adsorbed solvent, which is given as per cent of the coating. Therefore the adsorption relates to the thickness of the coating and the data meet the requirement for a reasonable comparison.

\section{X-ray powder diffraction}

X-ray powder diffraction measurements were performed on a Siemens D5000 powder diffractometer at room temperature using the $\mathrm{CuK}_{\alpha}$ line. 


\section{Acknowledgements}

We thank the German Ministry of Economics and Technology (BMWi, grant No. 16IN0218 'ChemoChips') for generous research funding. T. G. thanks Monika Mazik for her inspirational mentoring.

\section{Notes and references}

1 P. A. Wright, Microporous Framework Solids (RSC Materials Monographs), Royal Society of Chemistry, Cambridge, 2008.

2 J. W. Steed and J. L. Atwood, Supramolecular Chemistry, John Wiley \& Sons, Chichester, 2009, $2^{\text {nd }}$ ed.

3 K. E. Maly, J. Mater. Chem., 2009, 19, 1781.

4 R. W. Boyd, Nonlinear Optics, Academic Press, Oxford, 2008, $3^{\text {rd }}$ ed.

5 S. M. Auerbach, K. A. Carrado, P. K. Dutta (eds.), Handbook of Zeolite Science and Technology, CRC Press, 2003.

6 Metal-Organic Frameworks: Design and Application, ed. L. R. MacGillivray, Wiley, Hoboken, 2010.

7 Metal-Organic Frameworks: Applications from Catalysis to Gas Storage, ed. D. Farrusseng, Wiley-VCH, Weihnheim, 2011.

8 T. Hertzsch, J. Hulliger, E. Weber and P. Sozzani, Organic Zeolites, In: Encyclopedia of Supramolecular Chemistry, ed. J. Atwood, J. Steed, Marcel Dekker, New York, 2004.

9 G. Couderc and J. Hulliger, Chem. Soc. Rev., 2010, 39, 1545.

10 H. Mansikkamäki, M. Nissinen and K. Rissanen, Angew. Chem. Int. Ed., 2004, 43, 1243; C. Tedesco, I. Immediata, L. Gregoli, L. Vitagliano, A. Immirzia and P. Neri, CrystEngComm, 2005, 7, 449; F. Perret, A. D. Lazar, O. Shkurenko, K. Suwinska, N. Dupont, A. Navaza and A.W. Coleman, CrystEngComm, 2006, 8, 890; S. Kennedy and S. J. Dalgarno, Chem. Commun., 2009, 5275; S. J. Dalgarno, J. E.Warren, J. Antesberger, T. E. Glass and J. L. Atwood, New J. Chem., 2007, 31, 1891; C. Tedesco, L. Erra, M. Brunelli, V. Cipolletti, C. Gaeta, A. N. Fitch, J. L. Atwood and P. Neri, Chem. Eur. J., 2010, 16, 2371; S. Kennedy, G. Karotsis, C. M. Beavers, S. J. Teat, E. K. Brechin and S. J. Dalgarno, Angew. Chem. Int. Ed., 2010, 49, 4205; C. Tedesco, L. Erra, I. Immediata, C. Gaeta, M. Brunelli, M. Merlini, C. Meneghini, P. Pattison and P. Neri, Cryst. Growth Des., 2010, 10, 1527; R. de Zorzi, N. Guidolin, L. Randaccio and S. Geremia, CrystEngComm, 2010, 12, 4056; L. Erra, C. Tedesco, I. Immediata, L. Gregoli, C. Gaeta, M. Merlini, C. Meneghini, M. Brunelli, A. N. Fitch and P. Neri, Langmuir, 2012, 28, 8511; G. Brancatelli, R. de Zorzi, N. Hickey, P. Siega, G. Zingone, S. Geremia, Cryst. Growth Des., 2012, 12, 5111; A. Arduini, R. Bussolati, C. Massera, A. Pochini, F. Rapaccioli, A. Secchi and F. Ugozzoli, Supramol. Chem., 2013, ahead of Print, DOI: 10.1080/10610278.2013.814777.

11 G. R. Desiraju, T. Steiner, The Weak Hydrogen Bond in Chemistry and Structural Biology; IUCr Monographs on Crystallography; Oxford University Press: Oxford, U.K., 1999; Vol. 9, pp 29.

12 S. G. Bott, A. W. Coleman and J. L. Atwood, J. Am. Chem. Soc., 1986, 108, 1709.

13 For typical examples, see: A. Soi, W. Bauer, H. Mauser, C. Moll, F. Hampel and A. Hirsch, J. Chem. Soc., Perkin Trans. 2, 1998, 1471; S. Kumar, R. Varadarajan, H. M. Chawla, G. Hundal and M. S. Hundal, Tetrahedron, 2004, 60, 1001; T. Gruber, M. Gruner, C. Fischer, W. Seichter, E. Weber and P. Bombicz, New J. Chem., 2010, 34, 250, and references cited therein; C. Fischer, 
G. Lin, W. Seichter and E. Weber, Tetrahedron, 2011, 67, 5656; C. Fischer, W. Seichter and E. Weber, Beilstein J. Org. Chem., 2011, 7, 1602; C. Fischer, P. Bombicz, W. Seichter, F. Katzsch and E. Weber, Cryst. Growth Des., 2012, 12, 2445; S. Kennedy, C. M. Beavers, S. J. Teat and S. J. Dalgarno, Cryst. Growth Des., 2012, 12, 679; C. Fischer, P. Bombicz, W. Seichter and E. Weber, Struct. Chem., 2013, 24, 535.

14 R. K. Juneja, K. D. Robinson, C. P. Johnson and J. L. Atwood, J. Am. Chem. Soc., 1993, 115, 3818; B. Klenke, C. Näther and W. Friedrichsen, Tetrahedron Lett., 1998, 39, 8967; I. Columbus and S. E. Biali, J. Org. Chem., 2008, 73, 2598; M. P. Hertel, A. C. Behrle, S. A. Williams, J. A.R. Schmidt and J. L. Fantini, Tetrahedron, 2009, 65, 8657; C. Fischer, T. Gruber, W. Seichter and E. Weber, Org. Biomol. Chem., 2011, 9, 4347.

15 P. K. Thallapally and A. Naugia, CrystEngComm, 2001, 3, 114; L. Brammer, E. A. Bruton and P. Sherwood, Cryst. Growth Des., 2001, 1, 277.

16 O. R. Pedireddi, D. S. Reddy, B. S. Goud, D. C. Craig, A. D. Rae and G. R. Desiraju, J. Chem Soc., Perkin Trans. 2, 1994, 2353; F. F. Awwadi, R. D. Willett, K. A. Peterson and B. Twamley, Chem. Eur. J., 2006, 12, 8952.

17 C. Fischer, T. Gruber, D. Schindler, W. Seichter and E. Weber, Cryst. Growth Des., 2011, 11, 1989.

18 T. Harada, J. M. Rudziński and S. Shinkai, J. Chem. Soc., Perkin Trans. 2, 1992, 2109.

19 W. Verboom, A. Durie, R. J. M. Egberink, Z. Asfari and D. N. Reinhoudt, J. Org. Chem., 1992, 57, 1313.

20 A. Janshoff, H.-J. Galla and C. Steinem, Angew. Chem. Int. Ed., 2000, 39, 4004; K. Matsuura, K. Ariga, K. Endo, Y. Aoyama and Y. Okahata, Chem. Eur. J., 2000, 6, 1750; U. Schramm, C. E. O. Roesky, S. Winter, T. Rechenbach, P. Boeker, P. Schulze Lammers, E. Weber and J. Bargon, Sensors and Actuators B, 1999, 57, 233.

21 L. S. Yakimova, M. A. Ziganshin, V. A. Sidorov, V. V. Kovalev, E. A. Shokova, V. A. Tafeenko and V. V. Gorbatchuk, J. Phys. Chem. B, 2008, 112, 15569.

22 J. van Loon, A. Arduini, L. Coppi, W. Verboom, A. Pocchini, R. Ungaro, S. Harkema and D. N. Reinhoudt, J. Org. Chem., 1990, 55, 5639.

23 B. Tomapatanaget, T. Tuntulani and O. Chailapakul, Org. Lett., 2003, 5, 1539; B. Tomapatanaget and T. Tuntulani, Tetrahedron Lett., 2001, 42, 8105; P. Timmerman, J.-L. Weidmann, K. A. Jolliffe, L. J. Prins, D. N. Reinhoudt, S. Shinkai, L. Frish and Y. Cohen, J. Chem. Soc., Perkin Trans. 2, 2000, 2077.

24 SADABS, Siemens Area Detector Absorption Correction Program, Bruker AXS Inc., Madison, Wisconsin, USA, 2007.

25 G. M. Sheldrick, Acta Cryst., 2008, A64, 112.

26 G. Sauerbrey, Z. Phys., 1959, 155, 206. 